\title{
Brain Barriers and the Acute-Phase Response
}

\author{
Fernanda Marques, Margarida Correia-Neves, \\ João Carlos Sousa, Nuno Sousa and Joana Almeida Palha \\ Life and Health Sciences Research Institute (ICVS) \\ School of Health Sciences, University of Minho, Campus Gualtar, Braga \\ ICVS/3B's - PT Government Associate Laboratory, Braga/Guimarães \\ Portugal
}

\section{Introduction}

Recent findings on the brain response to peripheral inflammation have broadened our knowledge on the acute phase response. Notably, such advances may lead to the characterization of acute phase proteins in body fluids other than the blood. Among these, and of particular interest, is the cerebrospinal fluid (CSF) that fills the brain ventricles, the subarachnoid space and the spinal cord.

Acute phase response is a term used to describe, mostly, the liver response to an inflammatory insult, a process that, among other effects, ultimately results in changes in the plasma concentrations of various proteins. The triggers of liver response include the inflammatory insult and the molecules produced by multiple cell types, from inflammatory cells (e.g. neutrophils and macrophages), to endothelial and liver cells. As a consequence, the liver synthesizes a number of so-termed acute phase proteins that are classified, depending on whether their expression is increased or decreased, as positive or negative acute phase response proteins, respectively. Among the positive acute phase proteins are binding proteins, opsonins (e.g. C-reactive protein) and iron-related proteins [e.g. hepcidin (HAMP), ceruloplasmin, lipocalin 2 (LCN2) and ferritin]. The negative acute phase proteins also include binding proteins (e.g. albumin, transthyretin, retinol-binding protein), as well as iron-related proteins (e.g. transferrin). Nonetheless, acute phase response is not a process restricted to the liver. Throughout the years, acute phase proteins expression has also been found altered at the barriers of the brain. Most of these findings originated from work on the brain parenchyma response to inflammation (Quan et al., 1998; Nadeau \& Rivest, 1999); however, surprisingly, only recently were the barriers of the brain specifically considered in the overall response to peripheral inflammation. In this chapter we will address the contribution of the barriers of the brain in the acute-phase response to peripheral inflammatory stimuli.

\section{The barriers of the brain}

For a long time the brain was considered isolated from the immune system and unable to mount an immune response when challenged by invading pathogens. This immuneprivileged view of the brain was based on multiple observations: allografts survive longer in 
the central nervous system (CNS) than in other organs (Fuchs \& Bullard, 1988); the CNS lacks both lymphatic vessels and constitutive expression of major histocompatibility complex class I and II molecules on parenchymal cells (Perry, 1998) and, lastly, the CNS was thought to be devoid of classical antigen-presenting cells, such as dendritic cells (Matyszak \& Perry, 1996). The assumption of an immune-privileged system was further supported by the discovery of two barriers that confer invaluable protection to the brain: the blood-brain barrier (BBB) and the blood-CSF barrier (BCSFB) (reviewed by Abbott, 2005). While these barriers protect the brain from the fluctuations of blood components that are direct triggers of neuronal function (e.g. amino acids that function as neurotransmitters), it is now clear that they are much more than obstacles to the passage of molecules and cells into and out of the brain. Throughout this chapter we will highlight how both barriers actively participate in brain homeostasis. We will also explore the interplay between the immune and the central nervous systems in physiological and immune-challenged conditions.

\subsection{The blood-brain barrier}

The BBB is formed by the tight junctions between the endothelial cells of the capillaries that irrigate the brain parenchyma. Additionally, on a larger organizational level, the basal lamina, astrocytic end-feets, pericytes and neurons that surround the central BBB core, altogether make the neurovascular unit (Fig. 1A).

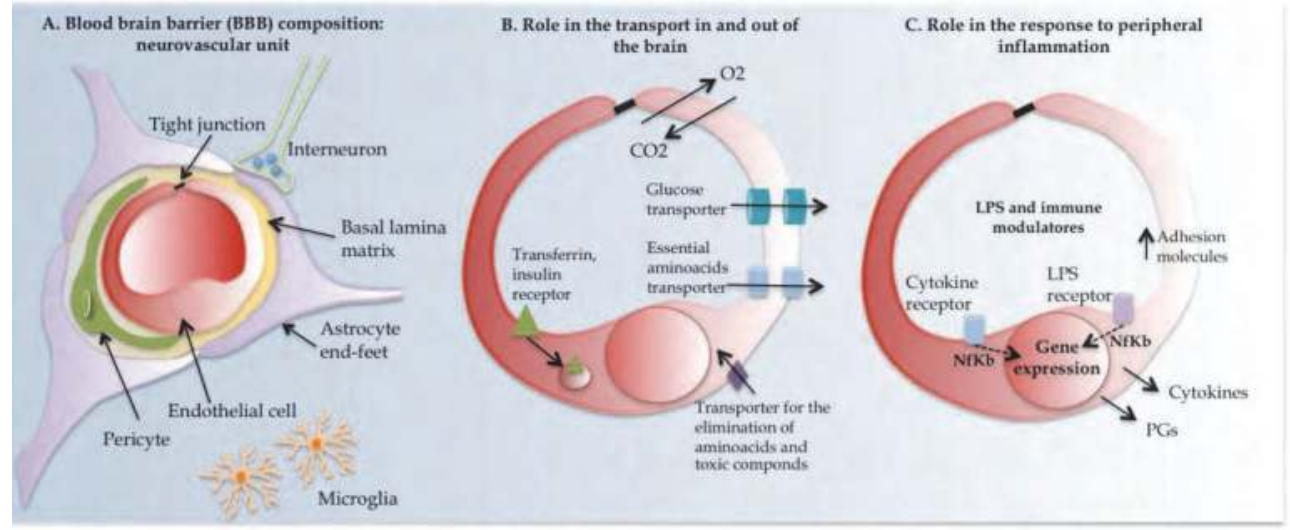

Fig. 1. Neurovascular unit composition, function and role in the response to peripheral inflammation. A. The blood-brain barrier (BBB) is formed by the tight junctions that connect the endothelial cells of the capillaries that irrigate the brain parenchyma. Together with the basal lamina, pericytes, and astrocytic end-feet it forms the neurovascular unit. B. The endothelial cells of the BBB have a crucial role in the transport of ions and solutes into and out of the brain. Some substances diffuse freely into and out of the brain parenchyma $\left(\mathrm{O}_{2}\right.$ and $\mathrm{CO}_{2}$ ), others such as nutrients need specific transporters, while molecules such as insulin, leptin and transferrin are transported by receptor-mediated endocytosis. Similarly, there are also transporters in the abluminal side of the endothelial cells described to participate in the removal of brain derived metabolites. Panel $\mathrm{C}$ depicts some of the pathways activated in the BBB in response to peripheral inflammation. 
With the exception of small lipophilic molecules, such as $\mathrm{O}_{2}$ and $\mathrm{CO}_{2}$ that freely diffuse across endothelial cells depending on their concentration gradient, the passage of bloodborn molecules through the BBB requires the presence of specific transporter or receptor systems. Nutrients, like glucose and amino acids enter the brain through specific transporters, while molecules such as insulin, leptin and transferrin are transported by receptor-mediated endocytosis (Pardridge et al., 1985; Zhang \& Pardridge, 2001). Conversely, similar mechanisms constitute a way out of the brain for molecules produced by the brain metabolism, via transporters and receptors located in the "brain side" of the endothelial cell (Fig. 1B). However, unlike the longer established mechanisms for the transfer of nutrients and molecules, the physiological passage of immune cells into the brain has not been shown until very recently. Specifically, it has been demonstrated that $T$ cells are able to breach both the BBB and the BCSFB to perform immune surveillance of the CNS (Engelhardt \& Coisne, 2011). More so, in pathological situations, including auto-immune brain disorders such as multiple sclerosis, the brain barriers become "leaky" leading to a drastic increase in the infiltration of immune cells into the brain (Engelhardt, 2006).

The brain barriers are needed; the neural milieu must be protected from the drastic concentration changes in blood molecules such as nutrients and ions. Nonetheless, the brain must also be able to rapidly respond to changes, since many of the humoral regulation centers are located within the brain. For these reasons, two brain regions lack the BBB: the circumventricular organs and the choroid plexus (CP). The $\mathrm{CP}$ will be addressed below, but we will first briefly describe the circumventricular organs. These brain regions, composed of the area postrema, median eminence, pineal gland, subfornical organ and lamina terminalis, are specialized neuroendocrine sites characterized by their small size and capillary irrigation (fenestration). They can either secrete or constitute sites of action for a variety of different hormones, neurotransmitters and cytokines, for which circumventricular organs are classified as either secretory or sensory, respectively. Compared to other brain regions, except the $\mathrm{CP}$, the circumventricular organs are unique in that they allow exchanges with the periphery. These exchanges are due to the permeability of the endothelium; nonetheless, circumventricular organs do not form an open door into the brain parenchyma given the presence of tight junctions between the tanycytes, the specialized ependymal cells that surround them (Brightman \& Kadota, 1992).

\subsection{The blood-cerebrospinal fluid barrier}

The $\mathrm{CP}$ is rapidly and actively exposed to any alteration in the blood milieu. It is formed by a monolayer of epithelial cells that originate from the ependymal cells that line the brain ventricles (two lateral ventricles, and the third and fourth ventricles). The $\mathrm{CP}^{\prime}$ s stroma is highly vascularised and populated by multiple cell types, from fibroblast to macrophages and lymphocytes or neutrophils, in proportions that reflect peripheral conditions (Emerich et al., 2005). The presence of tight junctions in the apical side of the $\mathrm{CP}^{\prime}$ s epithelial cells forms a barrier between the stroma and the CSF that is aptly termed the blood-CSF barrier (BCSFB) (Fig. 2A). Similarly to the BBB, the BCSFB prevents the paracellular passage of molecules and cells from the blood; however, in this case, into to the CSF. Of note, blood flow in the $\mathrm{CP}^{\prime} \mathrm{s}$ stroma is up to 10 times higher that of the other brain regions (Johanson et al., 2011). Again, resembling the BBB, the BCSFB also contains transporters and receptors; specifically, their presence in the basolateral and apical sides of the cell membrane allows the controlled passage of molecules in and out of the brain. In particular, the apical side of the epithelial cells faces the CSF and contains numerous villosities, which increase the surface contact area between the blood and the CSF. 
A. Blood cerebrospinal fluid barrier: choroid plexus characterization

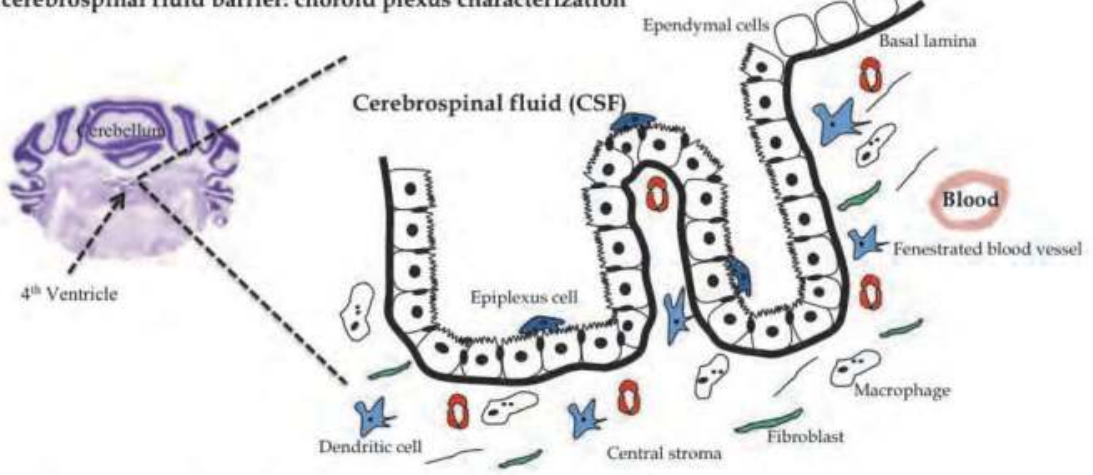

B. Role in the cerebrospinal fluid production

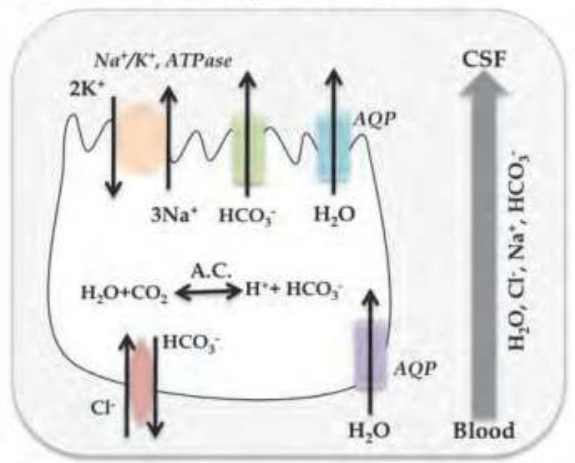

C. Role in response to peripheral inflammation

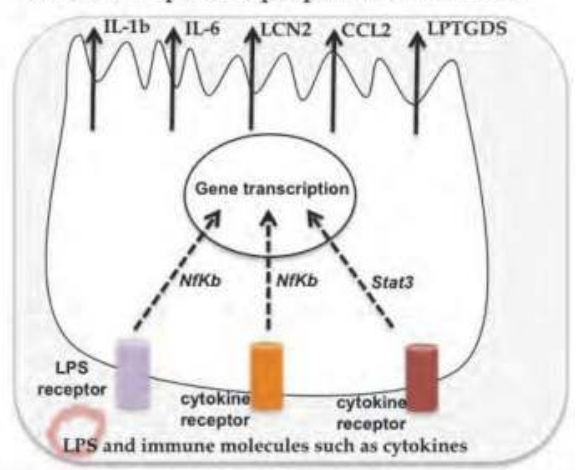

Fig. 2. Blood-cerebrospinal fluid barrier composition, function and role in the response to peripheral inflammation. A. The choroid plexus (CP) is formed by a monolayer of epithelial cells originating in the ependymal cells that line the brain ventricles, forming a closed structure - the stroma. The stroma is a connective tissue rich in fenestrated blood vessels and contains various cells types, such as macrophages, dendritic cells and fibroblasts. The $\mathrm{CP}$ epithelial cells are juxtaposed due to the apical localization of the tight junctions. While the apical side contacts with the cerebrospinal fluid (CSF), the basolateral side faces the fenestrated blood vessels. B. Choroid plexus has the required enzymes, transporters and channels to allow the passage of ions and water needed for the production of the CSF. Panel C. depicts aspects of the CP response to peripheral inflammation. In such conditions, lypopolysacharide (LPS) and immune modulators present in the blood (e.g. IL1- $\beta$ and IL-6), activate the basolateral side of the $\mathrm{CP}$ epithelial cells. In response, the $\mathrm{CP}$ transcriptome is altered resulting in the production of several proteins, some of which are then secreted into the CSF.

The CP's main function is the production of CSF, which fills the ventricles, the subarachnoid space and the spinal cord (Speake et al., 2001), ensuring an optimal environment for the CNS cells. In the adult human's CNS there are about $150 \mathrm{~mL}$ of circulating CSF that are renewed approximately four times daily (Wright, 1978). The CSF is a clear, slightly viscous fluid that surrounds the CNS and exchanges with the brain interstitial fluid. Given its 
circulation and exposure it participates in the delivery of nutrients into the brain and also in the removal of waste products generated within the brain. On the other hand, the CSF itself contains few cells and has a protein concentration about 10 times lower than that of the blood (Segal, 2001). The CP generates most of the CSF; the remainder $10-30 \%$ is of extrachoroidal origin, mostly from metabolism of the brain parenchyma and from the BBB (Johanson, 2008). Of notice, the CP in itself contributes to the composition of the CSF by secreting several carrier proteins and growth factors (reviewed by Chodobski \& Szmydynger-Chodobska, 2001). The high number of mitochondria present in the CP indicates its secretory activity. Additionally, the choroidal CSF secretion relies on the active production of an osmotic gradient that is mainly driven by carbonic anhydrase and $\mathrm{Na}^{+} / \mathrm{K}^{+}$ ATPase, and supported by the abundant expression of water channels (aquaporins) on the apical and basaloteral sides (Fig. 2B).

While the CSF system is expected to reflect brain homeostasis, recent evidence has revealed that it also reflects challenges induced in the periphery, including during response to peripheral inflammation which will next be discussed in detail.

\section{Acute phase response}

The term "acute phase" is associated with alterations in the liver transcription profile that, in response to an acute inflammatory stimulus, is reflected in the concentration of several plasma proteins. Several cells of the immune system also similarly contribute to changes in the concentration of plasma proteins, notably by secreting several cytokines and other immune-modulators that then act on many organ systems, including the CNS. The brain barriers are critical sites for cytokine signal transduction and for the initiation of the brain responses to peripheral inflammation. Circulating cytokines can act on the brain via various mechanisms that include: (i) fast transmission pathways, involving primary afferent neurons of the vagus nerve, innervating the site of inflammation; (ii) direct entry into the brain through the BBB or BCSFB via a saturable transport mechanism (cytokines are hydrophilic small proteins and are not expected to cross the BBB in the absence of a transport system); (iii) interactions within the circumventricular organs (reviewed by Hosoi et al., 2002); (iv) binding to receptors at the BBB (Gaillard, 1998) or BCSFB that activate intracellular mechanisms leading to the formation of short-lived substances, such as prostaglandins (PGs) and nitric oxide. These substances may diffuse across the brain barriers and play a role in the modulation of behavior and other brain disturbances observed during inflammatory states (for reviews, see Saper \& Breder 1992, 1994; Dantzer, 2001; Dantzer et al., 2008). Binding to the brain barriers receptors may also activate the production of new cytokines through the activation of transcription factors. This mechanism triggers the synthesis and secretion of cytokines and/or chemokines or other immune mediators by the barriers themselves (Marques et al., 2009b; Verma et al., 2006) (Fig. 1C and 2C).

The subject on whether peripheral inflammation triggers inflammation within the brain has raised the interest of investigators. Of notice, while studying particular events and molecules within the brain parenchyma, several groups have observed staining for various immune-mediators in the brain barriers; among these are tumor necrosis factor-alpha (TNFa) and interleukin 1-beta (IL1- $\beta$ ) in both CP and BBB endothelial cells (Marques et al., 2007; Nadeau \& Rivest 1999; Quan et al., 1999). In addition, “acute phase proteins" can be differently expressed in a tissue-specific manner in response to acute peripheral 
inflammation. For instance, while peripheral inflammation with the Gram negative bacterial cell wall component lypopolysacharide (LPS) (Dickson et al., 1986; Marques et al., 2007) results in decreased expression of the gene encoding for transthyretin in the liver (Birch \& Schreiber, 1986), it does not influence its expression in the CP. This differential response possibly reflects tissue-specific transcription factors regulation (Costa et al., 1990; Yan et al., 1990), while other signal transduction pathways may also be involved.

Despite all evidence on the barriers themselves as a site of homeostasis in response to peripheral stimulus, only recently have they been considered as a whole in mediating or participating in the response to peripheral inflammation. This will be next discussed in detail for the BCSFB, with particular emphasis on the de novo synthesizes of cytokines and of short-lived substances such as PGs. A special attention will be given to the $C P$, and particularly to its epithelial cells, because alterations in the $\mathrm{CP}$ response will ultimately be reflected in the composition of the CSF, which will impact on the brain parenchyma. A final note will be given to the $\mathrm{CP}$ as a neuroendocrine organ, given the strong evidence suggesting its participation in regional brain iron homeostasis, which is a novel concept.

\subsection{The choroid plexus response to acute peripheral inflammation: triggers, mediators and effectors}

The CP is ideally equipped to respond to peripheral stimulus and to communicate with the CNS since it is extremely well vascularised and because it produces most of the CSF. In addition, it possesses molecules important for leukocyte adhesion such as, lymphocyte selectin (L-selectin), intercellular adhesion molecule 1 (ICAM-1) and vascular cell adhesion molecule 1 (VCAM-1) that are found expressed at low levels in CP epithelial cells and can be up-regulated during inflammation (Endo et al., 1998; Wolburg et al., 1999). As such, the $\mathrm{CP}$ is suggested to be one of the first places for cell entry into the brain during inflammatory disease (Reboldi et al., 2009), which will also condition the CSF cell content.

A recent study characterized the complete $\mathrm{CP}$ transcriptome in the context of peripheral inflammation induced by a single intraperitoneal injection of LPS (Marques et al., 2009b). These results can be accessed in the GEOdatabase (GSE23714). In this work the kinetic CP transcriptome alterations were evaluated at 1, 3, 6, 12, 24 and $72 \mathrm{~h}$ after LPS injection. Interestingly, similarly to the liver, the $\mathrm{CP}$ showed a rapid and transient response. Specifically, the CP displayed a response to LPS that peaked between 3 to $6 \mathrm{~h}$ after LPS administration and rapidly returned to baseline after $72 \mathrm{~h}$. During this response, the expression of a large number of genes encodes for chemokines (such as chemokine C-C motif ligands 2, 3, 4, 7, 9, 11 and 19 and chemokine C-X-C motif ligands 1, 2, 9, 10, 13 and 16), cytokines (such as IL-1 $\beta$, IL6 and TNF- $\alpha$ ), adhesion molecules (Icam-1, selectin platelet and selection endothelial cell), acute phase proteins (serum amyloid A3, serum amyloid A1 and LCN2), and transporters (amino acid transporters) was altered (Marques et al., 2009b). Interestingly, several well-described pathways recognized to have diverse roles in the regulation of the immune system were also found altered in these conditions. Among these roles, we found the activation of the toll-like receptors (TLRs) and interleukin receptors leading to the subsequent activation of: (i) the transcription factor nuclear factor kappa $B$ $(\mathrm{NF}-\mathrm{k} \beta)$, which regulates the transcription of pro-inflammatory cytokines including TNF- $\alpha$, IL-1 $\beta$ and IL6; (ii) members of the mitogen-activated proteins kinase family (MAPK), notably p38 and JUN N-terminal kinase (JNK); (iii) the JAK/STAT signalling pathway, and (iv) the transcription factors known as interferon regulatory factors (IRFs) (Miyamoto et al., 1988). Termination of the CP response may be, at least in part, a consequence of the negative 
feedback inhibition of STAT signalling by SOCS/CIS (Naka et al., 2005), as some of the genes encoding for proteins in this pathway are up-regulated after LPS administration. A similar mechanism has been described in the BBB (Laflamme et al., 1999; Laflamme \& Rivest 1999; Lebel et al., 2000). Finally, of notice, the glucocorticoid receptor signalling pathway was also found altered, which is of interest given the role of the hypothalamus/pituitary/adrenal axis in the interplay between the immune and the central nervous systems in sickness behaviour.

Two interesting aspects should be taken into account: the blood-born molecules that trigger the $\mathrm{CP}$ response and the impact of the response itself. In this regard, particularly relevant are the molecules secreted into the CSF that ultimately reach and modulate responses within the brain parenchyma. With respect to triggers of the $\mathrm{CP}$ response, possible candidate molecules of interest are those that in response to an acute inflammatory stimulus have an increase in their blood concentration. Agents such as LPS, but also intrinsic immune modulators such as cytokines and chemokines, are potential triggers given that, for several of these (e.g. IL-1 $\beta$, IL- 6 and TNF- $\alpha$ ), the CP has receptors in the basolateral side of the epithelial cells (Marques et al., 2011). Accordingly, in vitro studies of primary cultures of rat CP epithelial cells exposed on the basolateral side (blood side in vivo) to LPS, or to serum collected from rats 3 and $6 \mathrm{~h}$ after LPS injection (Marques et al., 2009b), clearly showed that the CP response can be triggered by LPS directly and/or by blood-borne molecules. For example, while both LPS and serum from LPS-injected rats induced the expression of $I l 1 \beta$, Il6, and Cxcl1 in in vitro CP cultures, only the serum from LPS-injected rats had an effect on the expression of the transcription factor interferon regulatory factor 1 (Irf1). Of note, in vitro studies are a complement of the in vivo work since they permit a dissection of what is the real contribution of the $\mathrm{CP}$ epithelial cells; in in vivo studies the complete $\mathrm{CP}$ is usually studied, including not only the contribution of epithelial cells but also of all other cells present in the $\mathrm{CP}$ stroma. Among these are macrophages, dendritic cells (Hanly \& Petito, 1998; Ling et al., 1998; McMenamin, 1999) and fibroblasts. Epiplexus cells may also contribute, this time by interacting on the apical surface of the epithelial cells where they are found (Emerich et al., 2005; Ling et al., 1998). All of these cells, particularly macrophages, are able to produce immune modulators that can activate receptors in the basolateral membrane of the $\mathrm{CP}$ epithelial cells, ultimately contributing to the overall $\mathrm{CP}$ and brain response to inflammation.

Our initial work on the mouse $\mathrm{CP}$ response to peripheral inflammation, focused on proteins highly expressed and secreted by the CP. Of notice, we observed an increase in the prostaglandin D2 synthase (PTGDS) at 6, 12 and $24 \mathrm{~h}$ after peripheral acute injection of LPS, which returned to basal levels at $72 \mathrm{~h}$ (Marques et al., 2007) This was accompanied by increased CSF PTGDS concentration (Marques et al., 2007); in agreement with the kinetic profile of increased CSF concentration previously reported in rats after intraperitoneal injection of LPS (Ishizaka et al., 2001). PTGDS catalyzes the isomeration of prostaglandin H2 (PGH2) to produce prostaglandin D2 (PGD2), the major prostanoid in the CNS. Prostaglandin D2 can be transformed into multiple different prostaglandins, which themselves, can display anti- or pro-inflammatory properties. Among this is the conversion of PGD2 into the bioactive cyclopentenone-type prostaglandins of the J2-series such as 15deoxy- $\Delta^{12,14}$-prostaglandin J2 (15d-PGJ2). By repressing the expression of genes encoding for inflammatory mediators (e.g. TNF- $\alpha$ ) 15-dPGJ2 can be considered anti-inflammatory; however it has also been described to have pro-inflammatory through induction of cyclooxygenase 2 (COX-2) (Harris et al., 2002). In the context of the present discussion, the 
observation that endothelial cells with increased endogenous PGD2 levels downregulate the expression of VCAM-1 (Negoro et al., 2005) is of interest since it may contribute to the resolution of inflammation.

The first step of prostaglandin synthesis occurs through the action of COX-1 or COX-2 on arachidonic acid (AA), originating PGH2, which depending on the enzyme can be next transformed into multiple different prostaglandins. The COX-1 enzyme is ubiquitously expressed, while the COX-2 is mainly involved in inflammatory processes and therefore of particular relevance in the brain response to inflammation. Several studies have shown an increase in COX-2 expression in the BBB endothelial cells after central or systemic injection of endotoxin or cytokines (Cao et al., 1996; Laflamme et al., 1999). Additionally, the development of selective COX-2 inhibitors further suggests an important role for this cyclooxygenase in the BBB in response to acute inflammation; specifically, its inhibition lead to a decrease in the expression of tight junctions proteins in the endothelial cells of the barrier (Germann et al., 2008). In accordance, it has also been shown that COX-2 null-mice exhibit an increase in LPS-induced BBB disruption, mediated by an increase in matrix metalloproteinases 9 and 3 activities (Choi et al., 2010). These results further support the hypothesis that COX-2 may mediate the neuroinflammatory response, especially in maintaining the integrity of the neurovascular unit (Choi et al., 2010). Finally, cyclooxygenases can differentially modulate leukocyte recruitment into the inflamed brain (Choi et al., 2010). Interestingly, neither COX-1 nor COX-2 expression is altered in the CP transcriptome (that includes the epithelial cells of the BCSFB) in response to peripheral inflammation (Marques et al., 2009b). Altogether, these observations indicate that the BBB and BCSFB responses to inflammation may be different regarding the activation of pathways needed to maintain barrier integrity. Still, any alteration in the permeability properties may render the brain parenchyma more susceptible to noxious molecules and to the infiltration of immune cells. Reflecting the aspect of barrier integrity, it has been shown that a single LPS injection induces down-regulation in the transcripts of tight junction proteins and an increase in those encoding for extracellular matrix remodelling proteins such as metalloproteinases (Marques et al., 2009b).

In summary, the CP displays the adequate anatomical (at the interface between the blood and the CSF) and functional (membrane receptors, signal transduction pathways and secretory) setting to participate in the immune system-brain interplay. The relevance of such occurrence will depend on whether it is reflected in the CSF composition, as is the case for IL-6, CCL-2, PTGDS and LCN2 (Fig. 2C).

\subsection{Iron modulation at the brain barriers is part of the acute phase response}

While signalling in and out of the brain is currently accepted to occur at the brain barriers, evidence is accumulating on their participation in specific homeostatic circuitries. Particularly interesting is the possibility that the brain barriers participate on regulating brain iron homeostasis, which is relevant in neurodegenerative disorders where accumulation of iron has been reported.

As referred before, the kinetic response of the $\mathrm{CP}$ to peripheral inflammation resembles the liver acute phase response, in terms of duration and gene/pathways activation (Marques et al., 2009b). Remarkably, results from our studies show that, in response to inflammation, the $\mathrm{CP}$ seems to be a specific site for iron homeostasis. Specifically, it induces the de novo synthesis of major iron modulators that are not normally expressed and/or are expressed in 
very low levels, such as HAMP (hepcidin) and LCN2. Notably, these genes follow expression kinetics greatly similar to those of the liver (Ceciliani et al., 2002; Gabay \& Kushner 1999). A striking observation was that of the altered expression of LCN2. This protein is not present at the brain barriers in basal conditions, however its expression and secretion increase dramatically in response to a single injection of LPS in the periphery (Marques et al., 2008). LCN2 is an iron-related protein that was first described as an effective defence strategy for the body to control the growth of pathogens; by binding to iron-loaded siderophores, the iron chelators secreted by pathogens (Flo et al., 2004). Additionally, LCN2 was traditionally viewed as a liver acute phase protein (Liu \& Nilsen-Hamilton, 1995; Sunil et al., 2007), which was also produced by neutrophils, lung, spleen and uterus (Kjeldsen et al., 2000). However, from our work, LCN2 is now also known to be an acute phase protein in the endothelial cells of the BBB and in epithelial cells of the BCSFB (Marques et al., 2008) Namely, Lcn 2 mRNA levels are up regulated as early as $1 \mathrm{~h}$ after peripheral inflammation, returning to basal levels after $72 \mathrm{~h}$; in accordance, it is present in the CSF during the first 24 $\mathrm{h}$ post-stimuli, while undetectable in basal conditions (Marques et al., 2008). These observations suggested that LCN2 could be part of the host-innate immune response to infection at the barriers of the brain and in the CSF. These findings prompted us to further investigate the $\mathrm{CP}$ as a site of brain regional iron homeostasis, as will be next discussed.

During an immune response iron metabolism is tightly regulated. This regulation is crucial since iron is an essential element for the body homeostasis. Iron deficiency or excess can lead, respectively, to pathological conditions such as anemia or hemochromatosis. Furthermore, since no mechanism other than bleeding and cell renovation is known for iron excretion, the body maintains a tight iron regulation, although the mechanisms involved in this regulation have only recently been partially characterized. In particular, the liver was identified as the regulatory site for iron homeostasis through the synthesis and secretion of HAMP (Krause et al., 2000). Regulation of iron availability is made by the enterocytes, which determine the quantity of dietary iron that is absorbed. When iron stores are high, iron absorption is blocked; when low, iron absorption increases. This is controlled by the availability of ferroportin (the only iron exporter described), at the basolateral side of the enterocyte, which is regulated by HAMP (Krause et al., 2000). Circulating HAMP binds ferroportin on the surface of enterocytes, leading to its internalization and degradation, and blocking iron absorption into the bloodstream (Nemeth et al., 2004a). Under physiological conditions the level of HAMP is regulated by body iron requirements; however, HAMP expression can be modulated by pro-inflammatory cytokines such as IL- 6 and IL- $1 \beta$ during inflammatory response. This represents a host defence mechanism: by decreasing serum iron levels the host decreases iron availability for invading bacteria (Ganz, 2007). It follows that other cells of the body, specifically cells of the immune system, are equipped with the machinery capable of regulating iron homeostasis through the regulation of several ironrelated genes and proteins (Porto \& De Sousa, 2007). This is significant given the immune cells protective function and role in combating microorganisms. Still, the complete mechanism beyond HAMP regulation is far from fully understood.

The novel concept of regional iron homeostasis regulation, in the context of inflammation, adds another level of complexity to iron homeostasis. If confirmed, local brain iron homeostasis at the barriers might explain why diseases of iron accumulation in the periphery seem to spare the brain (Pientrangel, 2010). In the CP, ferroportin is localized in the apical side of the epithelial cells (Wu et al., 2004) and, in response to peripheral 
administration of LPS, the CP triggers a transient transcription of the HAMP encoding gene, which may result in inhibition of iron release into the CSF and the brain parenchyma.

In addition, the expression of several other iron-related genes, such as ferritins and ceruloplasmin, are also induced by the inflammatory stimulus. Finally, it should be noted that the stimulation of the Hamp gene is triggered not only directly by LPS but also by molecules whose expression increases in the blood in response to inflammation. An example of these is IL-6 (Marques et al., 2009a), a cytokine previously shown to regulate Hamp expression in the liver, upon interaction with the cognate cellular receptor, and through the STAT3 signalling transduction pathway (Kemna et al., 2005; Nemeth et al., 2003; Nemeth et al., 2004b). The same mechanism seems to be operational in the CP; primary cultures of rat CP epithelial cells when stimulated, in the basolateral side, with LPS or with IL-6, respond by inducing the expression of Hamp. The activation of the IL-6-mediated signalling transduction pathway was also observed in vivo when mice were acutely injected with LPS. In this case, increased phosphorylation of STAT3 was observed in the CP (Marques et al., 2009a). Of interest, Hamp expression was not induced when LPS or IL-6 were applied to the apical membrane of the CP epithelial cells, indicating that the receptors for LPS and IL-6 may be located in the basolateral (facing the blood) membrane.

Another well described pathway mediating Hamp expression is that of the SMAD4 complex. Members of this complex were initially discovered from observations that patients with mutations in hemochromatosis (Hfe), transferrin receptor type 2 (Tfr2), or hemochromatosis type 2 (juvenile) ( $\mathrm{Hjv}$ ) genes display iron deposition similar and consistent with elevated iron absorption, suggesting that these molecules may contribute to the regulation of Hamp expression. Interestingly, all of these molecules belong to the bone morphogenetic protein (BMP) signalling complex, which constitutes the most powerful mechanism known to activate Hamp transcription through SMAD4 activation (Verga Falzacappa et al., 2008). In support of these observations, TFR2 and the IL-6-mediated pathways seem to cross talk, at least in peripheral organs. Resembling its effect on HAMP regulation via the STAT3 signalling transduction pathway, IL-6 also functions as a stimuli in the SMAD4-mediated response. Wang et al. (2005) reported that the liver-specific disruption of Smad4 results in a markedly decreased Hamp expression when stimulated with IL-6. Similarly, a recent study using human hepatocyte cell cultures showed that mutations in the BMP-response element strongly hamper Hamp activation in response to IL-6 (Verga Falzacappa et al., 2008). In our $\mathrm{CP}$ transcriptome characterization study, no alterations were found in the expression levels of Hfe or Hjv; however, the expression of Tfr2 and of Smad4 was strongly increased after LPS stimulation (Marques et al., 2009a).

Although in-depth studies are necessary to fully characterize the $\mathrm{CP}^{\prime} \mathrm{s}$ regulation of iron homeostasis, altogether a mechanism is coming into view. In response to peripheral inflammation, the $\mathrm{CP}$, by secreting HAMP, may trigger the internalization of ferroportin, therefore preventing iron release into the CSF. Concomitantly, it secretes into the CSF other iron-related proteins, such as LCN2 and ceruloplasmin that, by themselves further restrict iron availability for potentially invading microorganisms.

The novel role here proposed for the CP-CSF barrier in regulating iron metabolism may also be present in diseases of the CNS in which iron accumulates or has been described to mediate neuronal toxicity. Among these are Alzheimer's disease and multiple sclerosis. Of interest, even though in different severity scales, both have underlying inflammatory processes. 


\section{Conclusion and future perspectives}

In the present chapter our goal was to highlight evidence that brain barriers participate in the communication of inflammatory stimuli into the brain. A few aspects, which were not specifically addressed, deserve a final mention, particularly that of neurogenesis and of multiple (or chronical) exposures to acute inflammatory stimuli/events. By modulating the composition of the CSF, or of the interstitial fluid of the brain, inflammatory stimuli induced in the periphery will influence neuronal function and processes such as neurogenesis. In this respect, in adults, LPS has been shown to alter the proliferative and migration profile of brain progenitor cells in the hippocampus (Fujioka \& Akema, 2010). Notably, several of the proteins whose concentration is altered in the CSF in response to acute inflammation are recognized as modulators of adult neurogenesis. Future studies will certainly bring us novel clues on the role of neurogenesis as well as its alteration under inflammatory conditions. Also, while the focus of this book is the acute response, it should be mentioned that throughout lifespan, individuals are exposed to several independent acute inflammatory events. It is still unknown how repeated exposure to inflammation may predispose to diseases of the CNS, and how are the barriers of the brain compromised or participants in such response. Nonetheless, it is now known that the response of the CP to repeated prolonged inflammatory stimuli is less drastic and broad than that of a single acute exposure (Marques et al, 2009c). Future studies should further elucidate on how the brain barriers' attenuate and/or mediate any deleterious effects to normal brain functioning.

\section{Acknowledgement}

The work referenced here was supported by grants from Fundação para a Ciência e a Tecnologia FCT/FEDER (POCTI/SAU-NEU/56618/2004; PTDC/SAU-NEU/105180/2008), and by the DANA Foundation, USA. Fernanda Marques is the recipient of posdoctoral fellowship from FCT (Portugal).

We are grateful to Dr. Nadine Santos for critically reviewing this manuscript.

\section{References}

Abbott, N. J. (2005). Dynamics of CNS barriers: evolution, differentiation, and modulation. Cellular and Molecular Neurobiology, Vol.25, No.1, pp. 5-23

Birch, H. E. \& Schreiber, G. (1986). Transcriptional regulation of plasma protein synthesis during inflammation. Journal of Biological Chemistry, Vol.261, No.18, pp. 8077-8080

Brightman, M. W. \& Kadota, Y. (1992). Nonpermeable and permeable vessels of the brain. NIDA Research Monograph, Vol.120, pp. 87-107

Cao, C.; Matsumura, K.; Yamagata, K. \& Watanabe, Y. (1996). Endothelial cells of the rat brain vasculature express cyclooxygenase-2 mRNA in response to systemic interleukin-1 beta: a possible site of prostaglandin synthesis responsible for fever. Brain Research, Vol.733, No.2, pp. 263-272

Ceciliani, F.; Giordano, A. \& Spagnolo, V. (2002). The systemic reaction during inflammation: the acute-phase proteins. Protein $\mathcal{E}$ Peptide Letters, Vol.9, No.3, pp. 211-223

Chodobski, A. \& Szmydynger-Chodobska, J. (2001). Choroid plexus: target for polypeptides and site of their synthesis. Microscopy Research and Technique, Vol.52, No.1, pp. 65-82 
Choi, S. H.; Aid, S.; Choi, U. \& Bosetti, F. (2010). Cyclooxygenases-1 and -2 differentially modulate leukocyte recruitment into the inflamed brain. Pharmacogenomics Journal, Vol.10, No.5, pp. 448-457, ISSN 1473-1150

Costa, R. H.; Van Dyke, T. A.; Yan, C.; Kuo, F. \& Darnell, J. E., Jr. (1990). Similarities in transthyretin gene expression and differences in transcription factors: liver and yolk sac compared to choroid plexus. Proceedings of the National Academy of Sciences, Vol.87, No.17, pp. 6589-6593, ISSN 0027-8424

Dantzer, R. (2001). Cytokine-induced sickness behavior: mechanisms and implications. Annals of the New York Academy of Sciences, Vol.933, pp. 222-234

Dantzer, R.; O'Connor, J. C.; Freund, G. G.; Johnson, R. W. \& Kelley, K. W. (2008). From inflammation to sickness and depression: when the immune system subjugates the brain. Nature Reviews Neuroscience, Vol.9, No.1, pp. 46-56

Dickson, P. W.; Aldred, A. R.; Marley, P. D.; Bannister, D. \& Schreiber, G. (1986). Rat choroid plexus specializes in the synthesis and the secretion of transthyretin (prealbumin). Regulation of transthyretin synthesis in choroid plexus is independent from that in liver. Journal of Biological Chemistry, Vol.261, No.8, pp. 3475-3478

Emerich, D. F.; Skinner, S. J.; Borlongan, C. V.; Vasconcellos, A. V. \& Thanos, C. G. (2005). The choroid plexus in the rise, fall and repair of the brain. Bioessays, Vol.27, No.3, pp. 262-274

Endo, H.; Sasaki, K.; Tonosaki, A. \& Kayama, T. (1998). Three-dimensional and ultrastructural ICAM-1 distribution in the choroid plexus, arachnoid membrane and dural sinus of inflammatory rats induced by LPS injection in the lateral ventricles. Brain Research, Vol.793, No.1-2, pp. 297-301

Engelhardt, B. (2006). Regulation of immune cell entry into the central nervous system. Results $\mathcal{E}$ Problems in Cell Differentiation, Vol.43, pp. 259-280

Engelhardt, B. \& Coisne, C. (2011). Fluids and barriers of the CNS establish immune privilege by confining immune surveillance to a two-walled castle moat surrounding the CNS castle. Fluids and Barriers of the CNS, Vol.8, No.1, pp. 4, ISSN 2045-8118

Flo, T. H.; Smith, K. D.; Sato, S.; Rodriguez, D. J.; Holmes, M. A.; Strong, R. K.; Akira, S. \& Aderem, A. (2004). Lipocalin 2 mediates an innate immune response to bacterial infection by sequestrating iron. Nature, Vol.432, No.7019, pp. 917-921

Fuchs, H. E. \& Bullard, D. E. (1988). Immunology of transplantation in the central nervous system. Applied Neurophysiology, Vol.51, No.6, pp. 278-296

Fujioka, H. \& Akema, T. (2010). Lipopolysaccharide acutely inhibits proliferation of neural precursor cells in the dentate gyrus in adult rats. Brain Research, Vol.1352, pp.35-42

Funk, C. D. (2001). Prostaglandins and leukotrienes: advances in eicosanoid biology. Science, Vol.294, No.5548, pp. 1871-1875, ISSN 0036-8075

Furuyashiki, T. \& Narumiya, S. (2009). Roles of prostaglandin E receptors in stress responses. Current Opinion in Pharmacology, Vol.9, No.1, pp. 31-38, ISSN 1471-4892

Gabay, C. \& Kushner, I. (1999). Acute-phase proteins and other systemic responses to inflammation. New England Journal of Medicine, Vol.340, No.6, pp. 448-454

Gaillard, R. C. (1998). Cytokines in the neuroendocrine system. International Reviews of Immunology, Vol.17, No.1-4, pp. 181-216

Ganz, T. (2007). Molecular control of iron transport. Journal of the American Society of Nephrology, Vol.18, No.2, pp. 394-400 
Germann, B.; Neuhaus, W.; Hofer-Warbinek, R. \& Noe, C. R. (2008). Applying blood-brain barrier in vitro models to study the influence of drugs on endothelial cells-effects of selected COX-inhibitors. Pharmazie, Vol.63, No.4, pp. 303-307, ISSN 0031-7144

Hanly, A. \& Petito, C. K. (1998). HLA-DR-positive dendritic cells of the normal human choroid plexus: a potential reservoir of HIV in the central nervous system. Human Pathology, Vol.29, No.1, pp. 88-93

Harris, S. G.; Padilla, J.; Koumas, L.; Ray, D. \& Phipps, R. P. (2002).Prostaglandins as modulators of immunity. Trends Immunology, Vol.23, pp. 144-150

Hosoi, T.; Okuma, Y. \& Nomura, Y. (2002). The mechanisms of immune-to-brain communication in inflammation as a drug target. Current Drug Targets Inflammation \& Allergy, Vol.1, No.3, pp. 257-262

Ishizaka, M.; Ohe, Y.; Senbongi, T.; Wakabayashi, K. \& Ishikawa, K. (2001). Inflammatory stimuli increase prostaglandin $\mathrm{D}$ synthase levels in cerebrospinal fluid of rats. Neuroreport, Vol.12, No.6, pp. 1161-1165,

Johanson, C. E.; Duncan, J. A., 3rd; Klinge, P. M.; Brinker, T.; Stopa, E. G. \& Silverberg, G. D. (2008). Multiplicity of cerebrospinal fluid functions: New challenges in health and disease. Cerebrospinal Fluid Research, Vol.5, pp. 10, ISSN 1743-8454

Johanson, C. E.; Stopa, E. G. \& McMillan, P. N. (2011). The blood-cerebrospinal fluid barrier: structure and functional significance. Methods in Molecular Biology, Vol.686, pp. 101131, ISSN 1940-6029

Kemna, E.; Pickkers, P.; Nemeth, E.; van der Hoeven, H. \& Swinkels, D. (2005). Time-course analysis of hepcidin, serum iron, and plasma cytokine levels in humans injected with LPS. Blood, Vol.106, No.5, pp. 1864-1866

Kjeldsen, L.; Cowland, J. B. \& Borregaard, N. (2000). Human neutrophil gelatinaseassociated lipocalin and homologous proteins in rat and mouse. Biochimica et Biophysica Acta, Vol.1482, No.1-2, pp. 272-283, ISSN 0006-3002

Krause, A.; Neitz, S.; Magert, H. J.; Schulz, A.; Forssmann, W. G.; Schulz-Knappe, P. \& Adermann, K. (2000). LEAP-1, a novel highly disulfide-bonded human peptide, exhibits antimicrobial activity. FEBS Letters, Vol.480, No.2-3, pp. 147-150

Laflamme, N.; Lacroix, S. \& Rivest, S. (1999). An essential role of interleukin-1beta in mediating NF-kappaB activity and COX-2 transcription in cells of the blood-brain barrier in response to a systemic and localized inflammation but not during endotoxemia. Journal of Neuroscience, Vol.19, No.24, pp. 10923-10930

Laflamme, N. \& Rivest, S. (1999). Effects of systemic immunogenic insults and circulating proinflammatory cytokines on the transcription of the inhibitory factor kappaB alpha within specific cellular populations of the rat brain. Journal of Neurochemistry, Vol.73, No.1, pp. 309-321

Lebel, E.; Vallieres, L. \& Rivest, S. (2000). Selective involvement of interleukin-6 in the transcriptional activation of the suppressor of cytokine signaling-3 in the brain during systemic immune challenges. Endocrinology, Vol.141, No.10, pp. 3749-3763

Ling, E. A.; Kaur, C. \& Lu, J. (1998). Origin, nature, and some functional considerations of intraventricular macrophages, with special reference to the epiplexus cells. Microscopy Research and Technique, Vol.41, No.1, pp. 43-56

Liu, Q. \& Nilsen-Hamilton, M. (1995). Identification of a new acute phase protein. Journal of Biological Chemistry, Vol.270, No.38, pp. 22565-22570 
Marques, F.; Falcao, A. M.; Sousa, J. C.; Coppola, G.; Geschwind, D.; Sousa, N.; CorreiaNeves, M. \& Palha, J. A. (2009a). Altered iron metabolism is part of the choroid plexus response to peripheral inflammation. Endocrinology, Vol.150, No.6, pp. 28222828, ISSN 1945-7170

Marques, F.; Rodrigues, A. J.; Sousa, J. C.; Coppola, G.; Geschwind, D. H.; Sousa, N.; Correia-Neves, M. \& Palha, J. A. (2008). Lipocalin 2 is a choroid plexus acute-phase protein. Journal of Cerebral Blood Flow \& Metabolism, Vol.28, No.3, pp. 450-455,

Marques, F.; Sousa, J. C.; Coppola, G.; Falcao, A. M.; Rodrigues, A. J.; Geschwind, D. H.; Sousa, N.; Correia-Neves, M. \& Palha, J. A. (2009b). Kinetic profile of the transcriptome changes induced in the choroid plexus by peripheral inflammation. Journal of Cerebral Blood Flow \& Metabolism, Vol.29, No.5, pp. 921-932

Marques, F.; Sousa, J. C.; Coppola, G.; Gao, F.; Puga, R.; Brentani, H.; Geschwind, D. H.; Sousa, N.; Correia-Neves, M. \& Palha, J. A. (2011). Transcriptome signature of the adult mouse choroid plexus. Fluids and Barriers of the CNS, Vol.8, No.1, pp. 10, ISSN 2045-8118

Marques, F.; Sousa, J. C.; Coppola, G.; Geschwind, D. H.; Sousa, N.; Palha, J. A. \& CorreiaNeves, M. (2009c). The choroid plexus response to a repeated peripheral inflammatory stimulus. BMC Neuroscience, Vol.10, pp. 135, ISSN 1471-2202

Marques, F.; Sousa, J. C.; Correia-Neves, M.; Oliveira, P.; Sousa, N. \& Palha, J. A. (2007). The choroid plexus response to peripheral inflammatory stimulus. Neuroscience, Vol.144, No.2, pp. 424-430

Matyszak, M. K. \& Perry, V. H. (1996). The potential role of dendritic cells in immunemediated inflammatory diseases in the central nervous system. Neuroscience, Vol.74, No.2, pp. 599-608

McMenamin, P. G. (1999). Distribution and phenotype of dendritic cells and resident tISSNue macrophages in the dura mater, leptomeninges, and choroid plexus of the rat brain as demonstrated in wholemount preparations. Journal of Comparative Neurology, Vol.405, No.4, pp. 553-562

Miyamoto, M.; Fujita, T.; Kimura, Y.; Maruyama, M.; Harada, H.; Sudo, Y.; Miyata, T. \& Taniguchi, T. (1988). Regulated expression of a gene encoding a nuclear factor, IRF1, that specifically binds to IFN-beta gene regulatory elements. Cell, Vol.54, No.6, pp. 903-913

Nadeau, S. \& Rivest, S. (1999). Regulation of the gene encoding tumor necrosis factor alpha (TNF-alpha) in the rat brain and pituitary in response in different models of systemic immune challenge. Journal of Neuropathology $\mathcal{E}$ Experimental Neurology, Vol.58, No.1, pp. 61-77

Naka, T.; Fujimoto, M.; Tsutsui, H. \& Yoshimura, A. (2005). Negative regulation of cytokine and TLR signalings by SOCS and others. Advances in Immunology, Vol.87, pp. 61-122

Negoro, H.; Shin, W. S.; Hakamada-Taguchi, R.; Eguchi, N.; Urade, Y.; Goto, A.; Toyo-Oka, T.; Fujita, T.; Omata, M. \& Uehara, Y. (2005). Endogenous prostaglandin D(2) synthesis decreases vascular cell adhesion molecule-1 expression in human umbilical vein endothelial cells. Life Sciences, Vol.78, pp. 22-29

Nemeth, E.; Rivera, S.; Gabayan, V.; Keller, C.; Taudorf, S.; Pedersen, B. K. \& Ganz, T. (2004a). IL-6 mediates hypoferremia of inflammation by inducing the synthesis of the iron regulatory hormone hepcidin. Journal of Clinical Investigation, Vol.113, No.9, pp. $1271-1276$ 
Nemeth, E.; Tuttle, M. S.; Powelson, J.; Vaughn, M. B.; Donovan, A.; Ward, D. M.; Ganz, T. \& Kaplan, J. (2004b). Hepcidin regulates cellular iron efflux by binding to ferroportin and inducing its internalization. Science, Vol.306, No.5704, pp. 2090-2093

Nemeth, E.; Valore, E. V.; Territo, M.; Schiller, G.; Lichtenstein, A. \& Ganz, T. (2003). Hepcidin, a putative mediator of anemia of inflammation, is a type II acute-phase protein. Blood, Vol.101, No.7, pp. 2461-2463

Pardridge, W. M.; Eisenberg, J. \& Yang, J. (1985). Human blood-brain barrier insulin receptor. Journal of Neurochemistry, Vol.44, No.6, pp. 1771-1778

Perry, V. H. (1998). A revised view of the central nervous system microenvironment and major histocompatibility complex class II antigen presentation. Journal of Neuroimmunology, Vol.90, No.2, pp. 113-121

Pientrangelo, A. (2010). Hereditary hemochromatosis: pathogenesis, diagnosis, and treatment. Gastroenterology, Vol.139, No.2, pp. 393-408

Porto, G. \& De Sousa, M. (2007). Iron overload and immunity. World Journal of Gastroenterology, Vol.13, No.35, pp. 4707-4715

Quan, N.; Stern, E. L.; Whiteside, M. B. \& Herkenham, M. (1999). Induction of proinflammatory cytokine mRNAs in the brain after peripheral injection of subseptic doses of lipopolysaccharide in the rat. Journal of Neuroimmunology, Vol.93, No.1-2, pp. $72-80$

Quan, N.; Whiteside, M. \& Herkenham, M. (1998). Time course and localization patterns of interleukin-1beta messenger RNA expression in brain and pituitary after peripheral administration of lipopolysaccharide. Neuroscience, Vol.83, No.1, pp. 281-293

Reboldi, A.; Coisne, C.; Baumjohann, D.; Benvenuto, F.; Bottinelli, D.; Lira, S.; Uccelli, A.; Lanzavecchia, A.; Engelhardt, B. \& Sallusto, F. (2009). C-C chemokine receptor 6regulated entry of $\mathrm{T}(\mathrm{H})-17$ cells into the CNS through the choroid plexus is required for the initiation of EAE. Nature Immunology, pp. 514-523

Saper, C. B. \& Breder, C. D. (1992). Endogenous pyrogens in the CNS: role in the febrile response. Progress in Brain Research, Vol.93, pp. 419-428; discussion 428-419, ISSN 0079-6123

Saper, C. B. \& Breder, C. D. (1994). The neurologic basis of fever. New England Journal of Medicine, Vol.330, No.26, pp. 1880-1886, ISSN 0028-4793

Segal, M. B. (2001). Transport of nutrients across the choroid plexus. Microscopy Research and Technique, Vol.52, No.1, pp. 38-48

Speake, T.; Whitwell, C.; Kajita, H.; Majid, A. \& Brown, P. D. (2001). Mechanisms of CSF secretion by the choroid plexus. Microscopy Research and Technique, Vol.52, No.1, pp. 49-59

Sunil, V. R.; Patel, K. J.; Nilsen-Hamilton, M.; Heck, D. E.; Laskin, J. D. \& Laskin, D. L. (2007). Acute endotoxemia is associated with upregulation of lipocalin $24 \mathrm{p} 3 / \mathrm{Lcn} 2$ in lung and liver. Experimental and Molecular Pathology, pp. 177-187

Verga Falzacappa, M. V.; Casanovas, G.; Hentze, M. W. \& Muckenthaler, M. U. (2008). A bone morphogenetic protein (BMP)-responsive element in the hepcidin promoter controls HFE2-mediated hepatic hepcidin expression and its response to IL-6 in cultured cells. The Journal of Molecular Medicine, pp. 531-540

Verma, S.; Nakaoke, R.; Dohgu, S. \& Banks, W. A. (2006). Release of cytokines by brain endothelial cells: A polarized response to lipopolysaccharide. Brain, Behavior, and Immunity, Vol.20, No.5, pp. 449-455, ISSN 0889-1591 
Wang, R. H.; Li, C.; Xu, X.; Zheng, Y.; Xiao, C.; Zerfas, P.; Cooperman, S.; Eckhaus, M.; Rouault, T.; Mishra, L. \& Deng, C. X. (2005). A role of SMAD4 in iron metabolism through the positive regulation of hepcidin expression. Cell Metabolism, Vol.2, No.6, pp. 399-409

Wolburg, K.; Gerhardt, H.; Schulz, M.; Wolburg, H. \& Engelhardt, B. (1999). Ultrastructural localization of adhesion molecules in the healthy and inflamed choroid plexus of the mouse. Cell and TISSNue Research, Vol.296, No.2, pp. 259-269

Wright, E. M. (1978). Transport processes in the formation of the cerebrospinal fluid. Reviews of Physiology, Biochemistry \& Pharmacology, Vol.83, pp. 3-34

Wu, L. J.; Leenders, A. G.; Cooperman, S.; Meyron-Holtz, E.; Smith, S.; Land, W.; Tsai, R. Y.; Berger, U. V.; Sheng, Z. H. \& Rouault, T. A. (2004). Expression of the iron transporter ferroportin in synaptic vesicles and the blood-brain barrier. Brain Research, Vol.1001, No.1-2, pp. 108-117

Yan, C.; Costa, R. H.; Darnell, J. E., Jr.; Chen, J. D. \& Van Dyke, T. A. (1990). Distinct positive and negative elements control the limited hepatocyte and choroid plexus expression of transthyretin in transgenic mice. Embo Journal, Vol.9, No.3, pp. 869878

Zhang, Y. \& Pardridge, W. M. (2001). Rapid transferrin efflux from brain to blood across the blood-brain barrier. Journal of Neurochemistry, Vol.76, No.5, pp. 1597-1600 


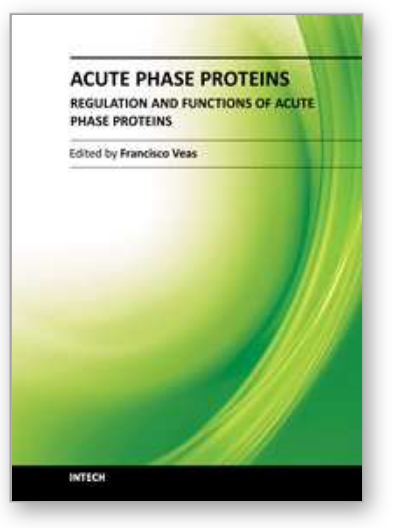

\author{
Acute Phase Proteins - Regulation and Functions of Acute Phase \\ Proteins \\ Edited by Prof. Francisco Veas
}

ISBN 978-953-307-252-4

Hard cover, 368 pages

Publisher InTech

Published online 03, October, 2011

Published in print edition October, 2011

The two volumes of Acute Phase Proteins book consist of chapters that give a large panel of fundamental and applied knowledge on one of the major elements of the inflammatory process during the acute phase response, i.e., the acute phase proteins expression and functions that regulate homeostasis. We have organized this book in two volumes - the first volume, mainly containing chapters on structure, biology and functions of APP, the second volume discussing different uses of APP as diagnostic tools in human and veterinary medicine.

\title{
How to reference
}

In order to correctly reference this scholarly work, feel free to copy and paste the following:

Fernanda Marques, Margarida Correia-Neves, João Carlos Sousa, Nuno Sousa and Joana Almeida Palha (2011). Brain Barriers and the Acute-Phase Response, Acute Phase Proteins - Regulation and Functions of Acute Phase Proteins, Prof. Francisco Veas (Ed.), ISBN: 978-953-307-252-4, InTech, Available from: http://www.intechopen.com/books/acute-phase-proteins-regulation-and-functions-of-acute-phaseproteins/brain-barriers-and-the-acute-phase-response

\section{INTECH}

open science | open minds

\section{InTech Europe}

University Campus STeP Ri Slavka Krautzeka 83/A 51000 Rijeka, Croatia Phone: +385 (51) 770447

Fax: +385 (51) 686166 www.intechopen.com

\section{InTech China}

Unit 405, Office Block, Hotel Equatorial Shanghai No.65, Yan An Road (West), Shanghai, 200040, China 中国上海市延安西路65号上海国际贵都大饭店办公楼 405 单元 Phone: +86-21-62489820

Fax: +86-21-62489821 
(C) 2011 The Author(s). Licensee IntechOpen. This is an open access article distributed under the terms of the Creative Commons Attribution 3.0 License, which permits unrestricted use, distribution, and reproduction in any medium, provided the original work is properly cited. 